\title{
HEALTH RELATED QUALITY OF LIFE IN CHILDREN WITH THALASSAEMIA ASSESSED ON THE BASIS OF SF-20 QUESTIONNAIRE IN YAZD, IRAN: A CASE-CONTROL STUDY
}

\author{
Mohammad Hossein Baghianimoghadam', Gholamreza Sharifirad², Zohre Rahaei', \\ Behnam Baghianimoghadam ${ }^{3}$, Hashem Heshmati ${ }^{4}$ \\ ${ }^{1}$ School of Health, Shahid Sadoughi University of Medical Sciences, Yazd, Iran \\ ${ }^{2} S c h o o l ~ o f ~ H e a l t h$, Isfahan University of Medical Sciences, Isfahan, Iran \\ ${ }^{3}$ Shahid Sadoughi University of Medical Sciences, Yazd, Iran \\ ${ }^{4}$ School of Health, University of Medical Sciences, Grorgan, Iran
}

\section{SUMMARY}

Backgrounds: Thalassaemia is becoming serious public health problem throughout the Mediterranean region, Middle East, Indian subcontinents and also South East Asia. Its' global prevalence is about 2 per 1,000 newborns while its' prevalence in Iran is 8-4 per 1,000 newborns. The aim of this study was to compare the Health Related Quality of Life (HRQOL) of thalassaemia patients with the HRQOL of healthy children in terms of essential core domains for pediatric HRQOL measurement.

Methods: This cross sectional study has been done in Yazd, Iran. 60 thalassaemia patients were selected randomly as case group and 120 healthy children as control group who were matched with respect to age and gender. The health related quality of life was measured with a self - administrated short - form questionnaire of Medical Outcomes study (SF-20). The SF-20 measure contains three dimensions about function (physical, social and role) and well-being (mental health, health perception and pain).

Results: The results of this study showed significant difference between all dimension of SF-20 and QOL of patients in the case and control group ( $p<0.001)$. The $Q O L$ in the case group was 75.05 ( $S D=9.38$ ), but in the control group was 93.4 (SD=6.42) out of 100.

Conclusions: The effect of thalassaemia on the HRQOL in affected children has been related to reduction of their physical, social and mental capabilities.

Key words: quality of life, SF-20, thalassaemia

Address for correspondence: G. Sharifirad, School of health, Isfahan University of Medical Sciences, Isfahan, Iran. E-mail: sharifirad@hlth.mui.ac.ir

\section{BACKGROUND}

Thalassaemia is a genetic blood disorder which can be fatal if not treated properly. It is characterized by no or low production of alpha or beta globin chains which form part of the hemoglobin structure in the red blood cells (1). The thalassaemia is becoming serious public health problem throughout the Mediterranean region, Middle East, Indian subcontinent and South East Asia (2, 3). Its' global prevalence is about 2 per 1,000 newborns while its' prevalence in Iran is $8-4$ per 1,000 births. Children with thalassaemia will appear well at birth, but anemia develops and progressively worses due to partial or total absence of hemoglobin. If this condition is left untreated, it may lead to an early death $(2,5)$. For children that survived, this condition impose serious implications on their health and related quality of life. Typically these children have to undergo blood transfusions at least once a month depending on the severity of illness. At these times they have to be hospitalized for a complete day. They also have to get desferal injections in iron chelation therapy to remove excess iron in their body because of frequent blood transfusions $(2,5,6)$.
Health Related Quality of Life (HRQOL) measurement is a multidimensional concept that focuses on the impact of disease and its' treatment in well being of an individual. The measures have been seen as a way for assessment of patients' perspectives about their disease and related treatments, their perceived needs for healthcare and their preferences for treatment and disease outcomes (7). However, a systematic review reports limited use of HRQOL measures in pediatric clinical trials or clinical practice (8). The review identified 18 trials which includes assessment of HRQOL on a variety of pediatric diseases but surprisingly there was not any study about thalassaemia, despite a complex nature of the illness.

An extensive and rigorous searches were done on websites and electronic databases that led to finding one paper dealing with HRQOL in adults with thalassaemia and another one about children.

Most of the research about thalassaemia involved interviews with patients, carers, nurses and doctors with the focus on strategy management of thalassaemia patients and their parents, the attitudes and expectations of these patients, counselling strategies 
for patients, parents and siblings and screening programs for thalassaemia. A recent study that was done on adults with thalassaemia suggests that treatment and cultural differences did not have a major effect on the quality of life in Cypriot thalassaemia patients (9). The research was conducted in a well established resource center with participation of 212 adult patients. Another study done in children compared the quality of life of patients with thalassaemia intermedia and patients with thalassaemia major and it was concluded that transfusion - independent thalassaemia patients also suffer from impairments that affect their quality of life (10). It was suggested that all patients with thalassaemia should undergo under QOL assessment so that interventions can be focused on affected domains. Since the limited research is done about the HRQOL of thalassaemia patients particularly in children, the aim of this study was to compare the HRQOL of thalassaemia children with their healthy counterparts in the essential core domains for pediatric HRQOL measurement: Physical and Social function, Role, Pain and Mental Health.

\section{METHODS}

This cross sectional study was conducted in Yazd city, Iran. The samples of this study were 60 Beta thalassaemia Major patients as case group and 120 healthy children as control group who were matched with respect to age and gender. The sample size was determined on the basis of similar studies $(11,12)$. The patients were interviewed when referred to receive blood transfusions and treatment at the Shaheed Rahnemon Hospital in Medical school of Yazd from May 2007 to August 2007.

The health related quality of life was measured with a SF-20 questionnaire. The SF-20 measure contains three dimensions about function (physical, social and role) and well-being (mental health, health perception and pain). It yields six numerical scores (0-100) for each parameter so that higher score indicates more pain and better functioning or wellbeing. The SF-20 has been validated in American and Finnish adult population $(13,14)$. The Finnish version of SF-20 has been translated by the Finnish National Health Institute. In order to ensure the clarity of the questionnaire, pilot testing of the questionnaire was performed using the coherence and consistency upon 5 thalassaemias' patients and 10 healthy children who were not included in the survey. After that, the questionnaire was modified on the basis of their feedback. Validity of the questionnaire was justified by 5 experts who were academic scholar. Reliability of the questionnaire was estimated using Cronbach's alpha technique which was 0.76 . Physical functioning was measured with items $3-8$ and the score range of $0-30$, role functioning with items 9 and 10 and the score range of $0-4$, social functioning with item 11 and the score range of $0-6$, mental health with items $12-16$ and the score range of $0-30$, health perception with items 1 and 17-20 and the score range of $0-25$ and physical pain with item 2 and the score range of $0-5$. Data were collected by a questionnaire in the case and control groups. Demographic data (age, gender) were collected from patient records and structured interviews.

For the healthy controls, the questionnaires were administered to children between 6 to 18 years old that were living in the neighbouring houses. Thus, this study investigates the HRQOL of children with thalassaemia and healthy children who com- pletely matched. Gathered data were transferred directly into SPSS (Statistical Package for Social Sciences). For data analysis, Chi-square, T-Test and Exact were used. Level of confidence interval was $95 \%$.

We obtained informed consent from all participants; in addition, the participants were assured that their responses would be kept confidential.

\section{RESULTS}

Out of about 90 recorded patients who were receiving treatment at the hospital only 60 were approached as 30 of them (total of 90) did not meet inclusion criteria (age, coming to hospital in the period of our research). Of the 120 questionnaires that were distributed among the control group (healthy children), 120 were filled in and returned.

Table 1 shows the demographic variables of 60 thalassaemia patients and 120 healthy controls. The healthy controls were slightly older, had higher education and were social and economically better off in comparison with the patient group. The mean age of the healthy controls was $13.62(\mathrm{SD}=2.82)$ and the age range was $6-18$. The mean age of the patients was $12.45(\mathrm{SD}=3.27)$ and the age range was $6-18$. The BMI of control group was slightly higher than in patient's group (19.69 and 19.1 respectively). In terms of gender, in both thalassaemia and control group, males' health status was better than that of females.

Table 2 presents the mean SF-20 scores of participants in the case and control groups. There was a significant difference in all dimensions of SF-20 and QOL between patients and controls $(\mathrm{p}<0.001)$. The QOL of the thalassaemia group was $75.05(\mathrm{SD}=9.38)$ while the QOL of the control group was 93.4 $(\mathrm{SD}=6.42)$ out of 100 .

The scores for dimensions of SF-20 and QOL of males and females are presented in Table 3. There was a significant difference between the physical and role dimensions in the case group $(p=0.004,0.001$, respectively).There was no significant difference between dimensions of SF-20 and QOL of males and females in the control group. Mean scores of all SF-20 dimensions and QOL of males and females in the control group was higher than in the case group. Mean QOL scores of males in the case group was (75.26, $\mathrm{SD}=8.91)$ while in the control group was $(93.52, \mathrm{SD}=6.07)$ and mean QOL scores of females in the case group was (74.76, $\mathrm{SD}=10.17)$ while in the control group was $(93.28, \mathrm{SD}=6.84)$. There was significant difference in all domains of SF-20 between males and females in the case and control groups except Pain in males and Role in females.

Health status data of the two groups is presented in Table 4. These findings show that the health status of the control group was better than the one of the case group (e.g. $63.3 \%$ versus $8.3 \%$ ).

\section{DISCUSSION}

Quality of life assessment in children especially in children with chronic illnesses such as thalassaemia is of particular importance. Use of the self reported health-related quality of life questionnaires in assessment of thalassaemia patients can be helpful to identify the impact of disease and administered 
Table 1. Demographic characteristics of case and control groups

\begin{tabular}{|c|c|c|c|}
\hline Variables & $\begin{array}{l}\text { Thalassaemia patients } \\
\qquad n=60\end{array}$ & $\begin{array}{l}\text { Healthy controls } \\
n=120\end{array}$ & $\mathrm{p}$-values \\
\hline Mean age (years) & $12.45(\mathrm{SD}=3.27)$ & $13.62(\mathrm{SD}=2.82)$ & 1.00 \\
\hline BMI $\left(\mathrm{kg} / \mathrm{m}^{2}\right)$ & $19.1(\mathrm{SD}=2.32)$ & $19.69(\mathrm{SD}=3.45)$ & 0.134 \\
\hline \multicolumn{4}{|l|}{ Gender } \\
\hline Female (n) & $25(41.7 \%)$ & $58(48.3 \%)$ & \multirow{5}{*}{0.148} \\
\hline \multicolumn{3}{|l|}{ Range (years) } & \\
\hline $6-9$ & $7(28 \%)$ & $22(37.9 \%)$ & \\
\hline $10-14$ & $12(48 \%)$ & $27(46.6 \%)$ & \\
\hline $15-18$ & $6(24 \%)$ & $9(15.5 \%)$ & \\
\hline Male (n) & $35(58.3 \%)$ & $62(51.7 \%)$ & \multirow{5}{*}{0.281} \\
\hline \multicolumn{3}{|l|}{ Range (years) } & \\
\hline $6-9$ & $12(34.3 \%)$ & $21(33.9 \%)$ & \\
\hline $10-14$ & $16(45.7 \%)$ & 27 (43.5\%) & \\
\hline $15-18$ & $7(20 \%)$ & $14(22.9 \%)$ & \\
\hline \multicolumn{3}{|l|}{ Education level } & \multirow{4}{*}{0.104} \\
\hline Primary school & $32(53.3 \%)$ & $50(41.7 \%)$ & \\
\hline Guidance school & $17(28.3 \%)$ & $54(45 \%)$ & \\
\hline High school & $11(18.4 \%)$ & $16(13.3 \%)$ & \\
\hline
\end{tabular}

Table 2. The mean SF-20 scores of participant in case and control groups

\begin{tabular}{|l|c|c|c|c|c|}
\hline Domains & $\begin{array}{c}\text { Thalassaemia patients } \\
\mathrm{n}=60 \\
\text { Mean score (SD) }\end{array}$ & $\begin{array}{c}\text { Healthy controls } \\
\mathrm{n=120} \\
\text { Mean score (SD) }\end{array}$ & Mean difference & $\begin{array}{c}\text { 95\% confidence inter- } \\
\text { val of the difference }\end{array}$ & p-values \\
\hline Physical & $26.27(4.22)$ & $29.89(0.71)$ & -3.62 & $(-4.46$ to -2.84$)$ & 0.0001 \\
\hline Role & $3.65(0.61)$ & $3.98(0.12)$ & -0.33 & $(-0.45$ to -0.22$)$ & 0.0001 \\
\hline Social & $4.7(1.76)$ & $5.8(0.52)$ & -1.11 & $(-1.45$ to -0.76$)$ & 0.0001 \\
\hline Mental & $21.93(4.28)$ & $26.39(3.46)$ & -4.46 & $(-5.63$ to -3.29$)$ & 0.0001 \\
\hline Health & $16.22(4.17)$ & $22.71(2.76)$ & -6.49 & $(-7.51$ to -5.46$)$ & 0.0001 \\
\hline Pain & $4.22(0.96)$ & $4.62(0.54$ & -0.4 & $(-0.62$ to -0.18$)$ & 0.004 \\
\hline Quality of life & $75.05(9.38)$ & $93.4(6.42)$ & -18.35 & $(-21.03$ to -15.68$)$ & 0.0001 \\
\hline
\end{tabular}

treatments from the children's perspective (15). There have also been discussions among pediatricians and child health researchers about the importance of children's perception of their own health. A recent study found that children as young as six years old can adequately understand and accurately report their own health and well being (16). Vincent and Higginson (17) stressed that any measurement of the quality of life in children should include questions about physical, social and psychological functioning of a child. They also emphasized that educational achievement, questions about sexuality, social and peer acceptance become significantly important as children grow older especially during adolescence.

Patients with chronic illness such as thalassaemia require self-management of their disease, which is a lifetime struggle to maintain and increase QOL. Treatment plans that inherently improve or include strategies to enhance patients' QOL may increase compliance, thereby improving patients' status $(18,19)$. If one of the goals of health care is to improve QOL, it seems important to understand how illness affects QOL1 and how we can control thalassaemia and increase the QOL. Indeed, one rationale for including QOL assessment in clinical trials is to train patients and promote their information and care skills to help them choosing treatment strategies that are consistent with their lifestyles.

There was not any previous study to compare the HRQOL of thalassaemia patients with healthy children in Iran. This is the first study providing evidences that the HRQOL of thalassaemia patients is lower than the HRQOL of healthy controls. The thalassaemia reduces the HRQOL in these children, i. e. their physical, social and mental activities by about $14 \%$ to $23 \%$. The findings of this study are consistent with the observations of Adriana Ismail et al, who described the effect of thalassaemia on HRQOL of children in terms of physical, social and school functioning by about $10 \%$ to $24 \%$ (20). This was confirmed by the study which determined that the scores of functioning (physical, social and 
Table 3. The distribution of mean and SD of domains of SF-20 and gender

\begin{tabular}{|l|l|c|c|c|c|c|c|c|}
\hline Gender & Domains & Health & Pain & Physical & Role & Social & Mental & QOL \\
\hline \multirow{2}{*}{ Male in case group } & Mean & 15.54 & 4.31 & 27.14 & 3.54 & 4.8 & 21.97 & 75.26 \\
\cline { 2 - 9 } & SD & 4.29 & 0.96 & 2.49 & 0.7 & 1.79 & 4.07 & 8.91 \\
\hline \multirow{2}{*}{ Female in case group } & Mean & 17.16 & 4.08 & 25.04 & 3.8 & 4.56 & 21.88 & 74.76 \\
\cline { 2 - 9 } & SD & 3.87 & 0.95 & 5.69 & 0.41 & 1.73 & 4.65 & 10.17 \\
\hline P-value & & 0.59 & 0.44 & 0.004 & 0.001 & 0.74 & 0.77 & 0.80 \\
\hline Male in control group & Mean & 22.42 & 4.63 & 29.9 & 3.98 & 5.82 & 26.76 & 93.52 \\
\cline { 2 - 9 } & SD & 0.96 & 0.52 & 0.76 & 0.13 & 0.43 & 3.11 & 6.07 \\
\hline \multirow{2}{*}{ Female in control group } & Mean & 23.02 & 4.6 & 29.88 & 3.98 & 5.79 & 26 & 93.28 \\
\cline { 2 - 9 }$y$ & SD & 2.52 & 0.56 & 0.65 & 0.13 & 0.61 & 3.79 & 6.84 \\
\hline P-value & 0.16 & 0.48 & 0.73 & 0.92 & 0.49 & 0.49 & 0.89 \\
\hline $\begin{array}{l}\text { P-value for men of case and } \\
\text { men of } 0.0001 \text { control group }\end{array}$ & & 0.0001 & 0.154 & 0.0001 & 0.0001 & 0.001 & 0.0001 & 0.0001 \\
\hline $\begin{array}{l}\text { P-value for female of case } \\
\text { group and female of control } \\
\text { group }\end{array}$ & & 0.0001 & 0.012 & 0.0001 & 0.148 & 0.0001 & 0.0001 & 0.0001 \\
\hline
\end{tabular}

Table 4. The health status of case and control groups

\begin{tabular}{|l|c|c|c|c|c|c|c|c|c|c|}
\hline \multirow{2}{*}{ Health status } & \multicolumn{2}{|c|}{ Bad } & \multicolumn{2}{c|}{ Moderate } & \multicolumn{2}{c|}{ Good } & \multicolumn{3}{c|}{ Very good } & \multicolumn{2}{c|}{ Excellent } \\
\cline { 2 - 22 } & $\mathbf{N}$ & $\%$ & $\mathbf{N}$ & $\%$ & $\mathbf{N}$ & $\%$ & $\mathbf{N}$ & $\%$ & $\mathbf{N}$ & $\%$ \\
\hline Case & 0 & 0 & 10 & 16.7 & 31 & 51.7 & 14 & 23.3 & 5.3 \\
\hline Control & 0 & 0 & 5 & 4.2 & 8 & 6.7 & 31 & 25.8 & 76 & 63.3 \\
\hline
\end{tabular}

role) in thalassaemia patients were lower than in their healthy counterparts and the difference was statistically significant. Pakbaz et al. (10) earlier suggested that emotional functioning is one of the impaired domains of thalassaemia patients and Adriana Ismail (20) showed that the emotional functioning scores of thalassaemia patients was low. Tsiantis et al. (21) also suggests that thalassaemia patients have their own coping strategies in dealing with their life but these coping strategies are not examined in this study. Our study discovered that the emotional functioning scores of healthy controls were also low. These scores are lower than the ones in healthy subjects in the United States $(22,23)$ and in the UK (24).

QOL of males and females in thalassaemia patients compared with healthy control group appears lower. The QOL of males was higher than in females, but there was no significant difference between them. There was, however, a significant difference between all domains of SF-20 in males and females both in case and control groups except Pain in males and Role in females. Thus, gender seems to have effect on the HRQOL of thalassaemia patients. These results are consistent with the findings of Alavi et al. (25). In their study the QOL of males was significantly higher than in females. The Psychosocial Health Summary score of the thalassaemia patients were also lower than in the healthy controls. This finding seems to support previous studies on psychosocial aspects of thalassaemia about necessity for providing more psychosocial support for thalassaemia patients $(28,29)$.

Our data show that the health status of the control group is much better compared to the case group. The health status of thalassaemia patients was excellent in $8.3 \%$, whereas in healthy controls the health status was excellent in $63.3 \%$. These results support findings of the study done by Pakbaz (10), who found that the health status for $41 \%$ of thalassaemia patients was not good.

Limitation of this study is that it was conducted at only one Thalassaemia Care Center in one hospital in Yazd. Thus, it might not be representative of the population of thalassaemia patients in the country.

\section{CONCLUSIONS}

The effect of thalassaemia on the HRQOL of children suffering from thalassaemia is reduction of their physical, social and mental capabilities by about $14 \%$ to $23 \%$.

\section{Acknowledgements}

Financial support for undertaking this survey was provided by the School of Health, Shahid Sadoughi University of Medical Sciences, Yazd, Iran. We gratefully acknowledge the contributions in the collection of data. Our special thanks to Mr. Hosseini for his valuable cooperation during the study.

\section{REFERENCE}

1. Clegg JB, Weatherall DJ. Thalassemia and malaria: new insights into an old problem. Proc Assoc Am Physicians. 1999 Jul-Aug;111(4):278-82.

2. Vullo R, Modell B, Georganda B. What is thalassaemia? 2nd ed. Nicosia: The Thalassaemia International Federation; 1995. 
3. Weatherall D. 2003 William Allan Award address. The Thalassemias: the role of molecular genetics in an evolving global health problem. Am J Hum Genet. 2004 Mar;74(3):385-92.

4. Haghshenas M, Zamany G. Thalassaemia. Shiraz: Medical University Press; 2008.

5. Anionwu E, Atkin K. The Politics of sickle cell and thalassaemia. Buckingham: Open University Press; 2001.

6. Saeed N. My life. United Kingdom Thalassaemia Society Matters. 2004;99:10

7. Bowling A. Current state of the art in quality of life measurement. In: Carr AJ, Higginson IJ, Robinson P, editors. Quality of life. London: BMJ Books; 2003.

8. Clarke SA, Eiser C. The measurement of health-related quality of life (QOL) in paediatric clinical trials: a systematic review. Health Qual Life Outcomes. 2004 Nov 22;2:66.

9. Telfer P, Constantinidou G, Andreou P, Christou S, Modell B, Angastiniotis M. Quality of life in thalassemia. Ann N Y Acad Sci. 2005;1054:27382.

10. Pakbaz Z, Treadwell M, Yamashita R, Quirolo K, Foote D, Quill L, et al. Quality of life in patients with thalassemia intermedia compared to thalassemia major. Ann N Y Acad Sci. 2005;1054:457-61.

11. Norman GR, Sloan JA, Wyrwich KW. Interpretation of changes in healthrelated quality of life: the remarkable universality of half a standard deviation. Med Care. 2003 May;41(5):582-92.

12. Machin D, Campbell M, Payers P, Pinol A. Statistical tables for the design of clinical studies. 2nd ed. Oxford: Blackwell Scientific Publications; 1997.

13. Stewart AL, Hays RD, Ware JE Jr. The MOS short-form general health survey. Reliability and validity in a patient population. Med Care. 1988 Jul;26(7):724-35

14. Aalto AM, Aro S, Ohinmaa A, Aro AR, Mahonen M. The validation of the SF-20 inert for health quality of life in the Finish general population. Helsinki: National Research \& Development Center for Welfare \& Health; 1997.

15. Fayers P, Machin D. Quality of life assessment, analysis and interpretation. Chichester: John Wiley and Sons; 2001.

16. Riley AW. Evidence that school-age children can self-report on their health. Ambul Pediatr. 2004 Jul-Aug;4(4 Suppl):371-6.

17. Vincent KA, Higginson IJ. Assessing quality of life in children. In: Carr AJ, Higginson IJ, Robinson P, editors. Quality of life. London: BMJ Books; 2003.
18. Jacobson AM, de Groot M, Samson JA. The evaluation of two measures of quality of life in patients with type I and type II diabetes. Diabetes Care. 1994 Apr;17(4):267-74.

19. Glasgow RE, Ruggiero L, Eakin EG, Dryfoos J, Chobanian L. Quality of life and associated characteristics in a large national sample of adults with diabetes. Diabetes Care. 1997 Apr;20(4):562-7.

20. Ismail A, Campbell MJ, Ibrahim HM, Jones GL. Health related quality of life in Malaysian children with thalassaemia. Health Qual Life Outcomes. 2006 Jul 2;4:39.

21. Motti-Stefanidi F, Christogiorgos S, Diareme S, Kolaitis G, Gilbert L, Samara C, et al. Coping in children with haemophilia and thalassaemis: a cross-national study. Rev Clin Pharmacol and Pharmacokinet. 2008;22(1):5-17.

22. Varni JW, Burwinkle TM, Katz ER, Meeske K, Dickinson P. The PedsQI in pediatric cancer: reliability and validity of the Pediatric Quality of Life Inventory Generic Core Scales, Multidimensional Fatigue Scale, and Cancer Module. Cancer. 2002 Apr 1;94(7):2090-106.

23. Varni JW, Burwinkle TM, Seid M. The PedsQL 4.0 as a school population health measure: feasibility, reliability, and validity. Qual Life Res. 2006 Mar;15(2):203-15.

24. Upton P, Eiser C, Cheung I, Hutchings HA, Jenney M, Maddocks A, et al. Measurement properties of the UK-English version of the Pediatric Quality of Life Inventory 4.0 (PedsQL) generic core scales. Health Qual Life Outcomes. 2005 Apr 1;3:22.

25. Alavi A, Parvin N, Khabiri S. A comparison between the view of parents of major thalassaemia patients about the QOL of their children in Shahre Kord, Iran. Journal of Medical University of Shahre Kord. 2006;4(22):3541.

26. Poddubnyĭ IV, Tolstov KN, Isaev AA, Iatsenko EA, Doniush EK, Kozlov MIu. Life quality of children with hematological diseases after laparoscopic splenectomy. Khirurgiia (Mosk). 2007;(7):41-4. (In Russian.)

27. Campbell MJ. Machin D. Medical statistics. A Commonsense approach. 3rd ed. West Sussex: John Wiley \& Sons Ltd; 2000.

28. Aydinok Y, Erermis S, Bukusoglu N, Yilmaz D, Solak U. Psychosocia implications of Thalassemia Major. Pediatr Int. 2005 Feb;47(1):84-9.

29. Goldbeck L, Baving A, Kohne E. Psychosocial aspects of betathalassemia: distress, coping and adherence. Klin Padiatr. 2000 SepOct;212(5):254-9. (In German.)

Received September 6, 2010 Accepted in revised form June 1, 2011 